HEAD AND NECK

\title{
Association between the increase in incidence of papillary thyroid carcinoma in Crete and exposure to radioactive agents
}

\author{
Associazione tra l'aumento dell'incidenza del carcinoma papillare della tiroide \\ e l'esposizione ad agenti radioattivi \\ E. P. Prokopakis ${ }^{1}$, A. Kaprana ${ }^{1}$, A. Karatzanis¹, G. A. Velegrakis¹ ${ }^{1}$ J. Melissas², G. Chalkiadakis ${ }^{3}$ \\ 'Department of Otorhinolaryngology, ${ }^{2}$ Department of Surgical Oncology, ${ }^{3}$ Department of General Surgery, \\ University Hospital of Crete, Heraklion, Crete, Greece
}

\section{SUMMARY}

The mean gamma-ray distribution in Crete during the years after the nuclear accident at Chernobyl and its correlation with the Papillary Thyroid Cancer (PTC) distribution was identified. A total of 4285 patients underwent total thyroidectomy in our centre between 1990 and 2012. Data of gamma-ray $(\mathrm{nSv} / \mathrm{h})$ distribution were selected from the Greek Statistical Authorisation. A geo-spatial statistical model was used to estimate the expected number of patients with PTC and Kriging interpolation prediction model to estimate their distribution. Geographical weighted regression was performed to estimate the risk of PTC in relation to gamma ray distribution. All factors that were examined were found to be statistically significant for PTC distribution in Crete. Gamma-ray was determined as a significant risk factor $(\mathrm{OR}=2.89 ; 95 \% \mathrm{CI}=1.682-4.989 ; \mathrm{p}$ value $=0.03)$. There is a significant correlation between gamma-ray exposure and the increased prevalence of the PTC suggesting that the former may have been a significant risk factor.

KEY WORDS: Papillary thyroid carcinoma $\bullet$ Crete $\bullet$ Gamma-ray

\section{RIASSUNTO}

In questo studio è stata valutata la distribuzione media di raggi gamma a Creta durante gli anni successivi al disastro nucleare di Cernobyl e la correlazione esistente con distribuzione di Carcinomi Papillari della Tiroide (PTC). Abbiamo valutato 4285 pazienti sottoposti a tiroidectomia presso il nostro centro tra il 1990 e il 2012. I dati riguardanti la distribuzione di raggi gamma (nSv/h) sono stati selezionati dall'Autorizzazione Statistica Greca. Per stimare il numero atteso di pazienti con PTC e la loro distribuzione sono stati utilizzati rispettivamente un metodo statistico geo-spaziale e il metodo di interpolazione di Kriging. I raggi gamma sono stati identificati come un fattore di rischio significativo $(O R=2,89 ; 95 \% C I=1,682-4,989 ; p$ value $=0,03)$. C'è pertanto una forte correlazione tra esposizione a raggi gamma e aumento della prevalenza di PTC.

PAROLE CHIAVE: Carcinoma papillare della tiroide $\bullet$ Creta $\bullet$ Raggi gamma

Acta Otorhinolaryngol Ital 2018;38:310-315

\section{Introduction}

An increased incidence of papillary thyroid carcinoma (PTC) in Crete, with a synchronous stability in the other carcinoma subtypes, is reported. Among the risk factors for developing thyroid cancer, the most established one is ionising radiation ${ }^{1-3}$. Data obtained from studies involving patients subjected to external radiation and more recently the Chernobyl accident, show that radiation plays an important role in thyroid carcinogenesis and principally in PTC ${ }^{1-5}$.
The island of Crete is the southernmost part of the European continent and is located in the eastern Mediterranean Sea. It spreads over an area of $8261 \mathrm{~km}^{2}$ and according to the latest census has 800,000 inhabitants.

We investigated the demographics of PTC as found in specimens of total thyroidectomies performed in an academic tertiary referral medical centre during the last 22 years, and estimated the risk of disease in relation to the gamma ray distribution in the years since 1990 . 


\section{Methods}

\section{Sample and study design}

This study was conducted by three departments (Department of Surgery, Department of Surgical Oncology, and Department of Otorhinolaryngology, Head and Neck Surgery) of an academic tertiary referral medical centre (University Hospital of Crete, Heraklion, Crete, Greece), among 4285 patients who underwent total thyroidectomy between 1990 and 2012. Patient records were placed in a database, which included demographics, history and biopsy results. Histopathological slides were reviewed thoroughly in all cases, with a special focus on PTC, since this type is the most frequent type. Patients who had previously undergone a partial thyroidectomy, or who were previously diagnosed with another primary carcinoma elsewhere, were excluded from the study. All patients included in the study were born before 1986 .

A geo-spatial statistical model was used to estimate the anticipated number of PTC cases in the whole region of Crete. Additionally, the mean gamma-ray distribution in Crete and its correlation to patient distribution was identified. The data were collected from the Greek Atomic Energy Commission (GAEC) ${ }^{6}$ Gamma-ray records. Data of gamma-ray $(\mathrm{nSv} / \mathrm{h})$ distribution were calculated as mean values for one year period per station in Crete. The analysis was performed in the Arcmap 10 Geographical Information Systems (GIS) ${ }^{7}$.

\section{Geo-spatial analysis}

Spatial distribution of the numbers of thyroidectomies performed per prefecture, as well as the number of thyroidectomies performed per 100,000 people, together with the basic demographic characteristics (age and gender) was performed using the Arc map's toolbox construction, in a thematic map. The island of Crete is divided in four prefectures, as is shown in Figure 1. Since patient records could probably be biased due to the fact that these were patients treated in a single medical centre on the island, a prediction map (Kriging interpolation) was constructed. The same procedure was also done for the gamma-ray records, as shown in Figure 2.

Kriging interpolation prediction model was applied using both patient and gamma-ray data to estimate their distribution throughout the island ${ }^{89}$. This was distributed in a prediction map after having verified the reliability of the prediction model through its semi-variogram and crossvalidation process. The Kriging interpolation model is a technique to interpolate the value of a random field (e.g. patients, gamma-ray values) at an unobserved location

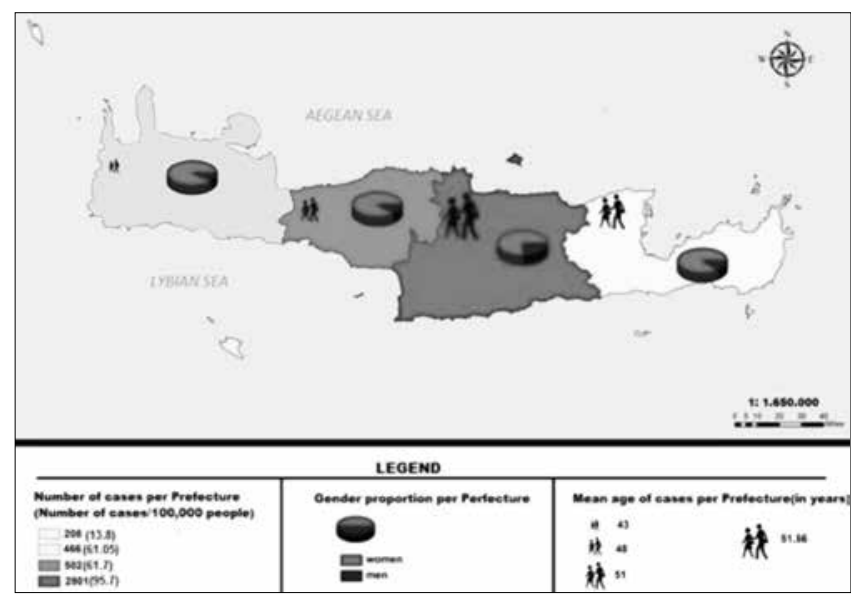

Fig. 1. Spatial distribution of thyroidectomy cases performed, age and gender. The island of Crete is divided in four prefectures, light grey = Chania, grey $=$ Rethymno, dark grey $=$ Heraklion, white $=$ Lasithi.

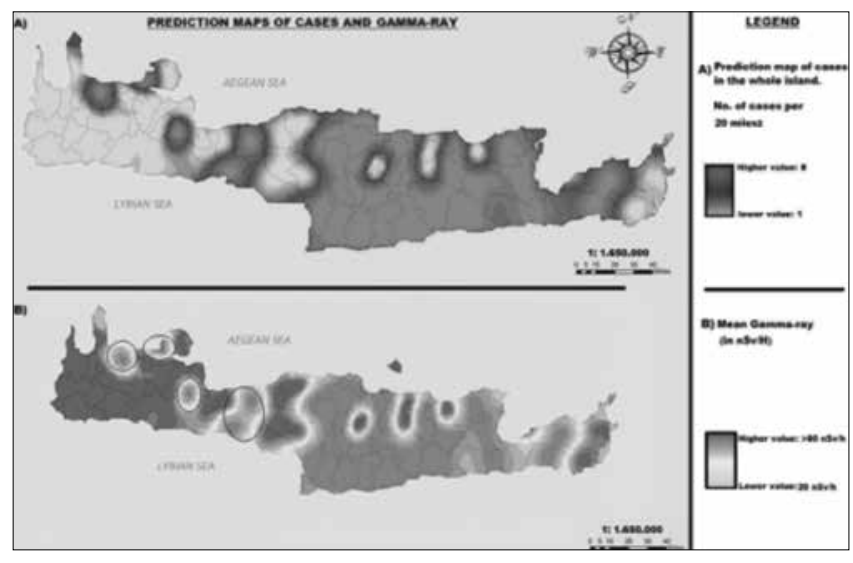

Fig. 2. (A) Prediction map of cases of expected number of thyroidectomies per $50 \mathrm{~km}^{2}$; (B) Prediction map of expected numbers of gamma-ray in nSv/h, in the island of Crete.

from observations of its value at nearby locations, using mathematical polynomials. Specifically, it estimates the number of cases in areas where there are no records from the database, based on known records and their spatial trends ${ }^{7-10}$. Through this procedure two sets of data were examined both as independent and dependent phenomena and the prediction was measured as the estimated number of patients per $50 \mathrm{~km}^{2}$ (randomly selected).

Finally, geographical weighted regression (GWR) was performed to estimate the risk of disease in relation to gamma ray distribution, as well as gender and age at a confidence level of $95 \%$. The GWR is a local version of spatial regression that generates parameters disaggregated by the spatial units of analysis. Therefore, it allows assessment of the spatial heterogeneity in the estimated 
relationships between the independent and dependent variables ${ }^{911}{ }^{12}$. The ethics committee for research of the University Hospital of Crete approved the study, based on the anonymous processing of personal health information.

\section{Results}

Our series consisted of 4285 patients; 308 patients were from out of Crete, for example islands close to Crete (Santorini, Rhodes), and were were excluded from the study. The percentage of PTC per prefecture was almost standard, about $25 \%$. That means 52 patients in prefecture of Chania, 117 patients in prefecture of Lasithi, 126 patients in the prefecture of Rethymno and 701 patients in prefecture of Heraklion. According to the population its prefecture as it seen in Figure 1, the distribution is heterogeneous among the different prefectures of the island of Crete, ranging from 13.8 patients per 100,000 people in Chania to 95.7 patients per 100,000 people in Heraklion. Rethymnon and Lasithi follow with 61.7 and 61.05 patients per 100,000 people respectively $(\mathrm{P}<0.001)$. Similarly, the age distribution of these patients varies significantly $(\mathrm{P}=0.02)$ among the different prefectures. The mean age of the patients is calculated at the year of 2013 from the database. The mean age of patients in Heraklion is much higher than in the other prefectures (mean age $=51.66)$. Conversely, the lowest mean age appears in Chania (mean age $=43$ ). The mean age of patients at the time of the Chernobyl accident falls within the range of 18 to 25 years old prospectively. On the other hand, gender distribution is almost homogeneous among the prefectures $(\mathrm{P}=0.63)$, with the proportion of men/women to be 1 (men) in 3 (women).

In order to deal with possible data bias (due to the fact that all patient records originate from a single hospital in Heraklion), the prediction map was produced and estimated the expected number of cases with PTC, in the overall region of Crete (Fig. 2A). Values range from 1 to 8 patients per $50 \mathrm{~km}^{2}$. A higher number of cases (incidents) were expected in all municipalities of Heraklion and in most of the municipalities of Lasithi (ranging from 4.5 to 8 cases per $50 \mathrm{~km}^{2}$ ), whereas lower numbers of patients were expected in Chania (almost 1 to 2 patients per $50 \mathrm{~km}^{2}$ ) and in Rethymnon (1.5 to 4 patients per $50 \mathrm{~km}^{2}$ ).

Using the same model, a prediction map was created for the mean gamma-ray distribution (Fig. 2B) with values ranging from 20 to $>80 \mathrm{nSv} / \mathrm{h}$. The gamma-ray distribution seems to follow a similar spatial pattern with the case distribution (prediction). Higher values appear in Heraklion and Lasithi (reaching even $60-80 \mathrm{nSv} / \mathrm{h}$ ), in contrast to Rethymnon and Chania, where lower values are expected although there are regions (hot spots) with extremely high values (70-80 $\mathrm{nSv} / \mathrm{h})$. Such regions are marked with red colour and are seen inside the administrative borders of the municipalities of Foinika and Nikiforou Foka in the prefecture of Rethymnon, and Chania, Acrotiriou, Platania and Krioneridas in the prefecture of Chania (outlined with a black circle in Figure 2). Several patients with PTC are observed all over the island identifying the regions where higher values of gamma-ray are distributed, highlighting a strong spatial variation.

Finally, in Table I and Figure 3, the results of the GWR are presented identifying both the risk factors and the high risk areas for PTC at a given time. As observed in Table I, all three factors examined were found to be statistically significant for the distribution of PTC in Crete. Women presented higher risk $(\mathrm{ExpB}=2.34 ; 95 \% \mathrm{CI}=1.359$ $3.028 ; p<0.001)$ than men, that is compatible to the current literature ${ }^{13}{ }^{14}$, while, for every year of increase in age, the risk for PTC increases almost 2.19 times (95\% $C I=1.092-4.517 ; p=0.04)$. Finally, the gamma-ray was

Table I. Gamma-ray, gender and age as possible risk factors of the disease in Crete according to the GWR model.

\begin{tabular}{lcc} 
Factors & Exp B $(\mathbf{9 5} \% \mathbf{C l})$ & P value \\
Gender & - & $<0.001$ \\
Men & 1 & - \\
Women & $2.34(1.359-3.028)$ & - \\
Age & $2.19(1.092-4.517)$ & 0.04 \\
Gamma-ray $(\mathrm{nSv} / \mathrm{h})$ & - & 0.03 \\
$<60$ & 1 & - \\
$>60$ & $2.89(1.682-4.989)$ & - \\
\hline $\mathrm{Cl}=$ Confidence Interval, Exp $B=\operatorname{Exp} B=$ exponentiation of the $B$ coefficient.
\end{tabular}

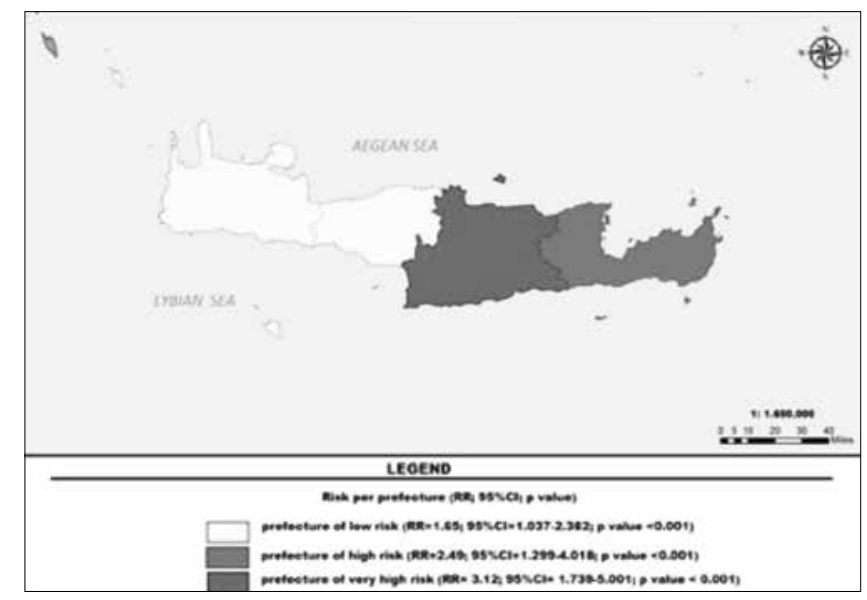

Fig. 3. Map of risk areas per prefecture, in relation to the risk factors, the observed and expected number of PTC, according to the GWR model (RR = relative risk, Exp $\mathrm{B}=$ exponentiation of the $\mathrm{B}$ coefficient, $\mathrm{Cl}=$ Confidence Interval). 
determined as a significant risk factor that has a proportional correlation with the case distribution $(p=0.03)$. This is particularly true for the high values of gamma-ray $(>60 \mathrm{nSv} / \mathrm{h}$ ), which present a higher risk for the disease $(\mathrm{OR}=2.89 ; 95 \% \mathrm{CI}=1.682-4.989 ; p=0.03)$.

Furthermore, the interaction of these risk factors in relation to the observed and estimated number of patients is demonstrated in a risk map (Fig. 3), which identifies the high risk areas for PTC. Moreover, it outlines the prefectures that call for potential intervention and further research. Thus, the prefectures were clustered in three groups according to the degree of estimated risk (yellow: low risk, orange: high risk, red: very high risk). Even though the prefectures of Chania and Rethymnon were found to present 1.65 times greater risk for PTC in comparison with areas with normal levels of gamma-ray exposure, they were characterised as relatively low risk (95\% CI $=1.037-2.383 ; p<0.001)$. Additionally, the prefecture of Lasithi presented higher risk $(\mathrm{RR}=2.49$; 95\% CI $=1.299-4.018 ; p<0.001)$, while the prefecture of Heraklion presented the highest risk $(\mathrm{RR}=3.12 ; 95 \%$ $\mathrm{CI}=1.739-5.001 ; p<0.001)$. All estimations were found to be statistically significant, identifying areas of high risk with reliability.

\section{Discussion}

The increased incidence of thyroid cancer in the island of Crete corresponds to an increase in PTC form of thyroid cancer ${ }^{13}$. It should be mentioned that an increased incidence of PTC was also noticed in the mainland of Greece, but has been correlated with the increased incidence of papillary microcarcinoma detection ${ }^{14}$, as well as changes in the diagnostic approach boosted by more careful histopathological examination ${ }^{15}$. Among the risk factors for thyroid cancer, the most established is ionising radiation ${ }^{16}$. Twenty-five years ago, on the $26^{\text {th }}$ of April 1986, a nuclear power plant catastrophe took place in Chernobyl, near Kiev, in the Ukraine leading to the worst nuclear power plant accident in history. Among the residents of Belarus, the Russian Federation and Ukraine, there had been, up to 2002, about 4000 cases of thyroid cancer reported in children and adolescents that were exposed to radiation at the time of the accident ${ }^{17}{ }^{18}$. Other data obtained from studies involving patients subjected to external radiation show that radiation plays an important role in thyroid carcinogenesis and principally in PTC ${ }^{18-20}$. Although in Greece there is no heavy industry and no use of radioactive agents, there was a remarkable geographical variability of radiation contamination. The radioactive agents should have been delivered to the island of
Crete because of the changes of the climatic phenomena in accordance with the climate changes that were occurred the last decades worldwide. For example, the increased radiation contamination in Crete may be correlated with the increased rainfall volume noticed from period after Chernobyl accident. It is noticeable that rainfall volume in May $1986(33.5 \mathrm{~mm})$ was 2.54 times higher than average (13.16) of the last 50 years, according to Hellenic National Meteorological service ${ }^{2122}$. The radiation contamination is certainly linked to the "coloured rain phenomenon", as in rain falling from clouds that contain dust from the Sahara Desert and North Africa region, almost covering each year at certain time the entire mainland of Greece 2223 .

Another possible mechanism of transmission is via underground water flow and seawater flow. According to recent research, increased concentrations of radioactive agents such as caesium-137 (Cs-137) and plutonium-239 were detected in the water column along the Algerian costs. The Cs-137 activity concentration in surface water increased from the west to the east, documenting a presence of modified Atlantic water in the region. Higher concentrations observed in deep waters may be due to an intrusion of Levantine intermediate water, which carries higher levels of Cs-137. These agents should be also transported by advection to maintain the observed ratios in deep waters ${ }^{24}$.

In the past, dietary patterns have been associated with the aetiology and increased incidence of thyroid cancer. Nowadays, Greek dietary patterns are rich in raw vegetables, thus protective against thyroid cancer, whereas no association with PTC is found ${ }^{25} 26$. It should also be mentioned that the available salt in Greece is iodine enriched; therefore, an association between nutrition and an increase in thyroid cancer cannot be easily established.

Additionally, overtreatment or overdiagnosis was ruled out in a previous study, and our study is based on true evidence of thyroid cancer and consist of patients who were definitely diagnosed with PTC after thyroidectomy. A silent subtype case of PTC represents an accidental finding with no clinical suspicion and sometimes possibly reflects an overdiagnosis. An upward trends of thyroid cancer worldwide has also been associated with increased diagnostic activity because of more sensitive diagnostic tests ${ }^{27}$. The use of more sensitive tests is associated with more accurate diagnosis of early stages of the disease. However, it may not explain the apparent increase in the incidence of larger lesions e.g. $>1 \mathrm{~cm}$. During the last three years in our hospital, we include elastography as a prerequisite test prior to thyroidectomy ${ }^{28}$. Thus, due to the extensive use of elastography, the need for preoperative FNA has been decreased ${ }^{29}$ and been used after performing elastography by unclear imaging results. 
This study has a high level of significance mainly due to its large sample size and the means of data analysis. Spatial statistics and mathematical polynomials are methods of high scientific significance that provide the ability to test for possible statistical errors and correct the final prediction model.

Conversely, there are also some limitations in this study, initially the fact that all the patient data were obtained only from one hospital in the Prefecture of Heraklion. Even though this is the main referral medical centre in Crete, there is still the General Hospital of Chania in which thyroidectomies are also performed. This is the main reason for the significantly lower number of thyroidectomies in the prefecture of Chania (Fig. 1). Therefore, we tried to overcome this limitation by estimation of the expected number of thyroidectomies (Fig. 2A). Additionally, these data were derived from different periods of time and were not analysed as contemporal data in this study. Thus, a spatio-temporal analysis of these data is suggested in a future study. At the same time, even though the data about gamma-ray were obtained from two reliable, official sources, the estimations were made from specific stations on the island covering most of its surface but not all of it. Although the interval radiation level was not higher than the international recommendation standards for radiation, which is $1 \mathrm{mSV} / \mathrm{y}$, in this study it is shown that there is increase of incidence of the PTA which corresponds to higher radiation levels. The methods of analyses selected for this study aimed to stay within with these limitations and provide data smoothing and estimation of expected values where no data were available.

The spatial regression model helps to identify the risk for disease with statistical confidence, while it offers an interesting result when it was compared with the distribution map (Fig. 1). It also should be mentioned that our hospital is the major institution in the island which refers from all other minor hospitals. In Figure 3, the prefectures of the lowest risk are those of Chania and Rethymnon. This is an important variation since the prefecture of Rethymnon had the second highest rates per 100,000 people (Fig. 1). This indicates a strong predisposition to the future number of patients expected to develop PTC, and to the influence of gamma-ray exposure as a risk factor.

\section{Conclusions}

By correlation of geographical distribution of PTC cases in the island with the geographical distribution of radiation, it is obvious that the gamma-ray distribution follows the spatial pattern of the disease and its estimated rates. This is verified not only by observing the two maps (Fig. 2), but also by the results of the GWR model that mathematically proves their significant correlation (Table I).

On the $11^{\text {th }}$ of March 2011 another nuclear accident took place, in Fukushima, Japan. In Japan, a number of prospective epidemiological studies on human health risks from low-dose radiation exposure and comprehensive health protection from radiation have been organised ${ }^{30}$. The public concerns about the long-term health effects of radioactive environmental contamination have increased based on the lessons learnt from the Chernobyl nuclear power plant accident. Our estimates are expected to be verified in the near future and if used by clinicians with the help of a field epidemiologist, could be the basis for future interventions, prevention, screening, or more aggressive treatments.

\section{Acknowledgements}

Dimitra Sifaki-Pistolla, PhD in the Department of Social and Family Medicine of the University Hospital of Crete for the statistical software support.

\section{References}

1 Remontet L, Estève J, Bouvier AM, et al. Cancer incidence and mortality in France over the period 1978-2000. Rev Epidemiol Sante Publique 2003;51:3-30.

2 Niedziela M, Korman E, Breborowicz D, et al. A prospective study of thyroid nodular disease in children and adolescents in western Poland from 1996 to 2000 and the incidence of thyroid carcinoma relative to iodine deficiency and the Chernobyl disaster. Pediatr Blood Cancer 2004;42:84-92.

3 Verger P, Catelinois O, Tirmarche M, et al. Thyroid cancers in France and the Chernobyl accident: risk assessment and recommendations for improving epidemiological knowledge. Health Phys 2003;85:323-9.

4 Liang J, Li Z, Fang F, et al. Is prophylactic central neck dissection necessary for $c N O$ differentiated thyroid cancer patients at initial treatment? A meta-analysis of the literature. Acta Otorhinolaryngol Ital 2017;37:1-8.

5 Jiwang L, Zhendong L, Shuchun L, et al. Clinicopathologic characteristics of familial versus sporadic papillary thyroid carcinoma. Acta Otorhinolaryngol Ital 2015;35:234-42.

6 Greek Atomic Energy Commission (GAEC). http://www. eeae.gr/gr/index.php?var=_main.

7 Mitchell A. The ESRI Guide to GIS Analysis. Vol 2. ESRI Press;2005.

8 Basu S, Reinsel GC. Regression models with spatially correlated errors. J Amer Stat Assoc 1994;89:88-99.

9 Jacquez GM. Current practices in the spatial analysis of cancer: flies in the ointment. Int J Health Geogr 2004;3:22.

10 Aissiou M, Périé D, Gervais J, et al. Development of a pro- 
gressive dual kriging technique for $2 D$ and $3 D$ multi-parametric MRI data interpolation. Comput Methods Biomech Biomed Engin 2013;2:69-78.

11 Silva RA, West JJ, Zhang Y, et al. Global premature mortality due to anthropogenic outdoor air pollution and the contribution of past climate changes. Environ Res Lett 2013;8:034005.

12 Mobley L, Kuo TM, Urato M, et al. Community contextual predictors of endoscopic colorectal cancer screening in the USA: spatial multilevel regression analysis. Int $\mathrm{J}$ Health $\mathrm{Ge}-$ ogr 2010;9:44.

13 Boutzios G, Vasileiadis I, Zapanti E, et al. Higher incidence of tall cell variant of papillary thyroid carcinoma in Graves' disease. Thyroid 2014;24:347-54.

14 Pazaitou-Panayiotou K, Iliadou PK, Chrisoulidou A, et al. The increase in thyroid cancer incidence is not only due to papillary microcarcinomas: a 40-year study in 1778 patients. Exp Clin Endocrinol Diabetes 2013;121:397-401.

15 Griniatsos J, Tsigris C, Kanakis M, et al. Increased incidence of papillary thyroid cancer detection among thyroidectomies in Greece between 1991 and 2006. Anticancer Res 2009;29:5163-9.

16 United Nations Scientific Committee on the Effects of Atomic Radiation. UNSCEAR 2008 Report. Effects of ionizing radiation. Vol II. http://www.unscear.org/unscear/en/publications/2008_2.html.

17 Rahu K, Hakulinen T, Smailyte G, et al. Site-specific cancer risk in the Baltic cohort of Chernobyl cleanup workers, 1986-2007. Eur J Cancer 2013;49:2926-33.

18 Prokopakis EP, Lachanas VA, Velegrakis GA, et al. Increased incidence of papillary thyroid cancer among total thyroidectomies in Crete. Otolaryngol Head Neck Surg 2007;136:560-2.

19 Williams ED, Pacini F, Pinchera A. Thyroid cancer following Chernobyl. J Endocrinol Invest 1995;18:144-6.

20 Dinets A, Hulchiy M, Sofiadis A, et al. Clinical, genetic and immunohistochemical characterization of 70 Ukrainian adult cases with post-chornobyl papillary thyroid carcinoma. Eur J Endocrinol 2012;166:1049-60.

21 Hellenic National Meteorological Service. http://www.hnms. gr/hnms/greek/index_html.

22 Papastefanou C, Manolopoulou M. The radioactivity of coloured rain in Thessaloniki, Greece. Sci Total Environ 1989;80:225-7.

23 Papastefanou C, Manolopoulou M, Stoulos S, et al. Coloured rain dust from Sahara Desert is still radioactive. J Environ Radioact 2001;55:109-12.

24 Noureddine A, Benkrid M, Maoui R, et al. Radionuclide tracing of water masses and processes in the water column and sediment in the Algerian Basin. J Environ Radioact 2008;99:1224-32.

25 Markaki I, Linos D, Linos A. The influence of dietary patterns on the development of thyroid cancer. Eur J Cancer 2003;39:1912-9.

26 Ron E, Kleinerman RA, Boice JD Jr, et al. A populationbased case-control study of thyroid cancer. J Natl Cancer Inst 1987;79:1-12.

27 Verkooijen HM, Fioretta G, Pache JC, et al. Diagnostic changes as a reason for the increase in papillary thyroid cancer incidence in Geneva, Switzerland. Cancer Causes Control 2003;14:13-7.

28 Ron E, Lubin JH, Shore RE, et al. Thyroid cancer after exposure to external radiation: a pooled analysis of seven studies. Radiat Res 1995;141:259-77.

29 Azizi G, Keller J, Lewis M, et al. Performance of elastography for the evaluation of thyroid nodules: a prospective study. Thyroid 2013;23:734-40.

30 Yamashita S, Suzuki S. Risk of thyroid cancer after the Fukusima nuclear power plant accident. Respir Investig 2013;51:128-33.

Received: February 21, 2017 - Accepted: July 20, 2017

Address for correspondence: Emmanuel P. Prokopakis, Department of Otorhinolaryngology, University of Crete School of Medicine, A Building, 3rd Floor, University Hospital of Crete, University Avenue, 71110 Heraklion, Crete, Greece. Tel. +30 6932237622. Email: eprokopakis@uoc.gr 